\title{
The influence of a compacted plow sole on saturation excess runoff
}

\author{
K. Verbist*, W.M. Cornelis, W. Schiettecatte, G. Oltenfreiter, \\ M. Van Meirvenne, D. Gabriels \\ Department of Soil Management and Soil Care, Ghent University, Coupure Links 653, B-9000 Ghent, Belgium \\ Received 19 December 2006; received in revised form 13 June 2007; accepted 3 July 2007
}

\begin{abstract}
Subsoil compaction due to conventional tillage techniques and its relation to subsurface flow and runoff was investigated on a sloped field. The presence of a plow sole was confirmed by significantly higher penetration resistances between 20 and $40 \mathrm{~cm}$ depth, a significantly higher soil bulk density and a $14 \%$ decrease in drainage pore space compared to the top layer. Ring infiltrometer measurements also confirmed a significant reduction of the saturated hydraulic conductivity at $30 \mathrm{~cm}$ depth, indicating a limited permeability. With the use of an extensive grid of tensiometers, matric heads were monitored and the occurrence of a temporary water table on top of the plow sole was confirmed in a number of cases. Equipotential lines in the top saturated layer indicated the occurrence of subsurface flow parallel to the slope surface in a downward direction. For the whole measuring period, when a perched water table was observed, $91 \%$ of the rainfall events caused runoff and this number increased with increasing rainfall intensity. For low and medium rainfall intensities $\left(<10 \mathrm{~mm} \mathrm{~h}^{-1}\right), 66 \%$ and $63 \%$ of the runoff events were related to saturation of the top soil. Therefore, it was concluded that over a period of 20 months saturation excess runoff as a result of subsoil compaction was an important contributor to surface runoff and soil loss.
\end{abstract}

(C) 2007 Elsevier B.V. All rights reserved.

Keywords: Soil compaction; Subsurface flow; Tensiometer; Saturation excess runoff

\section{Introduction}

Subsurface flow has long been identified as an important hydrological process in hillslopes (Kirkby, 1978; Higgins and Coates, 1990), caused by partly saturation of the soil profile. When slight changes occur in soil texture, perched water tables can be formed due to reductions in hydraulic conductivity at the interfaces between soil layers (Hagerty, 1991). These perched water tables are identified to contribute to surface runoff processes when found near to the soil surface (Kirkby,

\footnotetext{
* Corresponding author. Tel.: +329264 60 40; fax: +3292646247

E-mail address: Koen.Verbist@UGent.be (K. Verbist).
}

1978; Kirkby and Chorley, 1967), producing variable source areas (VSA) (Hewlett and Hibbert, 1967). The combined contributions of subsurface flow exfiltrating at the surface and those contributions from direct rainfall onto the saturated portions are termed 'saturation excess runoff' (Dunne and Black, 1970), in contrast to the infiltration driven runoff, named infiltration excess runoff' (Horton, 1933). However, the process of saturation excess runoff is mostly related to wetlands and riparian zones (Dunne et al., 1975; Coates, 1990; Wilson et al., 1991), as well as to shallow soils (Matsushi et al., 2006; Retter et al., 2006).

In continuously tilled agricultural soils, subsoil compaction has been identified as an important cause of soil degradation (McGarry, 2001), reducing the pore 
volume and soil structure (Pagliai et al., 2003). It has been shown that especially the largest pores, also called structural pores (Fies, 1971), are eliminated by compaction (Guérif, 1987; Pagliai, 1987), thereby increasing the proportion of small pores, causing a flattening of the soil water retention curve (Assouline et al., 1997), due to a changing pore geometry. This reduction of porosity causes a decrease in the saturated hydraulic conductivity (Pagliai et al., 2000; Lin et al., 1996) and the soil drainage capacity (Voorhees et al., 1986; Radford et al., 2000; Arvidsson, 2001; House et al., 2001) as well as an increase of soil bulk density (Pagliai et al., 2004). Due to a reduction of permeability, subsoil compaction can cause the formation of a perched water table near to the soil surface, which may result in an increase of surface runoff (saturation excess runoff) and subsurface flow, both promoting soil erosion, as reported by Fullen (1985) for a loamy sand in east Shropshire, England.

Nevertheless, the impact of subsoil compaction on surface runoff processes needs further investigation, especially since subsoil compaction is ubiquitous in many conventionally tilled agricultural systems, such as the ones observed in the Belgian loess belt, and knowledge of its influence on hydrological processes at the field scale is still lacking. This paper further addresses the relationship between subsoil compaction and the occurrence of a temporary saturated zone on the one hand and surface runoff and soil loss on the other hand, based on field data collected during a period of 20 months.

\section{Materials and methods}

\subsection{Field site}

In 2000, an experimental field plot was installed at Maarkedal $\left(50^{\circ} 46^{\prime} 29^{\prime \prime} \mathrm{N}, 3^{\circ} 35^{\prime} 11^{\prime \prime} \mathrm{S}\right)$, situated in the loess belt of Belgium, for monitoring surface runoff and erosion losses under different management conditions (Verbist et al., 2003; Verbist and Schiettecatte, 2004). Prior to the installation of the experimental plots, the field had been conventionally tilled during at least 20 years. Before sowing in springtime, the field was plowed to a depth of $30 \mathrm{~cm}$ using a moldboard, followed by harrowing. The crop rotation applied was potatowheat-corn-corn-corn. The experimental field plot was $100 \mathrm{~m}$ long and $2 \mathrm{~m}$ wide, and was located on a steep, slightly convex slope, with a slope gradient of $14 \%$. During the research period considered in this study, i.e. from 1 December 2002 until 30 September 2004, the field plot was kept bare and was not tilled.

\subsection{Soil and sampling}

The soil physical characteristics that allow identification of subsoil compaction and the existence of a plow sole (Jorajuria et al., 1997) were measured at the experimental site. Forty undisturbed soil samples were taken using standard sharpened steel $100-\mathrm{cm}^{3}$ Kopecky rings at different depths $(0-5 \mathrm{~cm}, 15-20 \mathrm{~cm}, 25-30 \mathrm{~cm}$, $32-37 \mathrm{~cm}, 37-42 \mathrm{~cm}, 43-48 \mathrm{~cm}, 70-75 \mathrm{~cm}$ and 90 $95 \mathrm{~cm}$ ) at $25 \mathrm{~m}$ intervals along the slope transect to determine soil texture, bulk density, the soil water retention curve and the drainage pore space, defined as part of the total pore space (\% pores $>50 \mu \mathrm{m}$ ) which will drain when the matric head is equal to or higher than $-60 \mathrm{~cm}$ water head $(\mathrm{pF}$ 1.78). Morphological analysis of resin-impregnated soil images have shown that compaction reduces larger pores, but mainly the elongated and continuous transmission pores (50$500 \mu \mathrm{m}$ ) and to a lesser extent those $<50 \mu \mathrm{m}$ (Pagliai et al., 2000), making drainage pore space a particular strong indicator for reduced permeability due to soil compaction.

Soil texture was determined with the pipette method (Gee and Bauder, 1986), whereas organic matter measurements were based on the Walkley and Black (1934) method. The soil water retention curve was established using the sand box apparatus (Eijkelkamp Agrisearch Equipment, Giesbeek, the Netherlands ${ }^{1}$ ) for matric heads between -10 and $-100 \mathrm{~cm}$ water head, and with pressure chambers (Soilmoisture Equipment, Santa Barbara, CA, USA) for matric heads between $-200 \mathrm{~cm}$ and $-15 \times 10^{3} \mathrm{~cm}$ water head. In Table 1 , the soil textural characteristics from the experimental site are presented. The field plot has a rather homogeneous silt loam soil texture, with a gradual increase in clay content until a depth of $0.4 \mathrm{~m}$, and is classified as an Alfisol (USDA, 1998). The soil is low in organic carbon content (O.C.), whereas $\mathrm{CaCO}_{3}$ content is negligible.

The saturated hydraulic conductivity of the surface was determined using a 5 by $2 \mathrm{~m}$ large rainfall simulator and was calculated from the infiltration characteristic, obtained from the difference between measured precipitation and runoff (Verbist et al., 2003). Nine repetitions were made during the measuring period, resulting in an average value of $22.0 \pm 6.0 \mathrm{~mm} \mathrm{~h}^{-1}$. Field saturated hydraulic conductivities at different soil depths were determined using the Model 2800 Guelph Permeameter with the $10 \mathrm{~cm}$ Ring Infiltrometer

\footnotetext{
${ }^{1}$ Mention of company names is for the convenience of the reader and does not constitute any endorsement from the authors.
} 
Table 1

Average soil characteristics of the experimental field at Maarkedal $(n=40)$

\begin{tabular}{|c|c|c|c|c|c|}
\hline Depth $(\mathrm{cm})$ & $\begin{array}{l}\text { Clay }(0-2 \mu \mathrm{m}) \\
\left(\mathrm{g} \mathrm{kg}^{-1}\right)\end{array}$ & $\begin{array}{l}\text { Silt }(2-50 \mu \mathrm{m}) \\
\left(\mathrm{g} \mathrm{kg}^{-1}\right)\end{array}$ & $\begin{array}{l}\text { Sand }(50-2000 \mu \mathrm{m}) \\
\left(\mathrm{g} \mathrm{kg}^{-1}\right)\end{array}$ & $\begin{array}{l}\mathrm{CaCO}_{3} \\
\left(\mathrm{~g} \mathrm{~kg}^{-1}\right)\end{array}$ & $\begin{array}{l}\text { O.C. } \\
\left(\mathrm{g} \mathrm{kg}^{-1}\right)\end{array}$ \\
\hline $0-5$ & $159 \pm 19^{b}$ & $614 \pm 16$ & $227 \pm 9$ & $2.5 \pm 1.8^{\mathrm{c}}$ & $19.7 \pm 2.9$ \\
\hline $15-20$ & $159 \pm 18$ & $611 \pm 37$ & $230 \pm 22$ & $2.5 \pm 1.6^{\mathrm{c}}$ & $22.1 \pm 2.1$ \\
\hline $25-30$ & $180 \pm 35$ & $637 \pm 38$ & $183 \pm 49$ & $2.5 \pm 1.6^{\mathrm{c}}$ & $14.9 \pm 7.5$ \\
\hline $32-37$ & $190 \pm 44$ & $650 \pm 48$ & $160 \pm 64$ & $2.5 \pm 1.8^{\mathrm{c}}$ & $11.9 \pm 8.2^{\circ}$ \\
\hline $37-42$ & $210 \pm 51$ & $654 \pm 27$ & $136 \pm 47$ & $1.8 \pm 1.4^{\mathrm{c}}$ & $7.3 \pm 4.9^{\circ}$ \\
\hline $43-48$ & $209 \pm 42$ & $655 \pm 35$ & $136 \pm 31$ & $1.8 \pm 1.4^{\mathrm{c}}$ & $5.9 \pm 3.0^{\circ}$ \\
\hline $70-75$ & $188 \pm 34$ & $672 \pm 41$ & $140 \pm 26$ & $2.0 \pm 2.3^{\mathrm{d}}$ & $4.1 \pm 2.8^{\mathrm{c}}$ \\
\hline $90-95$ & $182 \pm 26$ & $644 \pm 50$ & $173 \pm 25$ & $1.3 \pm 1.6^{\mathrm{d}}$ & $2.7 \pm 1.8^{\mathrm{c}}$ \\
\hline
\end{tabular}

${ }^{\mathrm{a}}$ O.C. is the percentage of organic carbon.

${ }^{b}$ Values preceded by \pm give the standard deviation.

c Variation coefficient is higher than 0.5 .

${ }^{\mathrm{d}}$ Variation coefficient is higher than 1.0.

Attachment (Soilmoisture Equipment Corp., Santa Barbara, USA). A total of 18 measurements were performed: at depths of $15 \mathrm{~cm}, 30 \mathrm{~cm}$ and $45 \mathrm{~cm}$ below the surface and at positions of $5 \mathrm{~m}, 55 \mathrm{~m}$ and $85 \mathrm{~m}$ along the slope (starting from the lower edge of the plot), measurements were carried out in duplicate. For these sets of measurements lognormal statistical distributions were assumed, as is common for in situ measurements of hydraulic conductivities (Warrick and Nielsen, 1980).

To evaluate the compaction of the soil, penetration resistance was measured using a digital penetrologger (Eijkelkamp Agrisearch Equipment, Giesbeek, The Netherlands). This device measures the resistance of the soil (MPa) against a cone with a surface of $1 \mathrm{~cm}^{2}$ which is driven into the soil at a constant speed. The penetration resistances were measured until the maximum operating depth of $0.8 \mathrm{~m}$, resulting in 80 data points for each measurement. This was done in threefold at positions of $5 \mathrm{~m}, 10 \mathrm{~m}, 15 \mathrm{~m}, 20 \mathrm{~m}$, $25 \mathrm{~m}, 35 \mathrm{~m}, 45 \mathrm{~m}, 55 \mathrm{~m}, 70 \mathrm{~m}$ and $85 \mathrm{~m}$ along the slope. To obtain a continuous representation over the entire field plot, subsoil penetration resistances were interpolated using an ordinary kriging technique (Goovaerts, 1997) with a direction-dependent variogram model (Pannatier, 1996). Because penetration resistance measurements are highly dependent on the water content of the soil (Ide et al., 1985; Bennie and Burger, 1988), the soil water content was determined at the same time by means of a TRIME-FM measuring device (IMKO Micromodultechnik GmbH, Ettlingen, Germany). The penetrometer measurements were performed at field capacity to minimize the influence of soil moisture on the measured penetration resistances and because penetration resistances at field capacity are considered a reference point for comparisons among different soil types (Smith et al., 1997).

\subsection{Field monitoring}

In order to monitor the water status, ten sets of tensiometers were installed at $5 \mathrm{~m}, 10 \mathrm{~m}, 15 \mathrm{~m}, 20 \mathrm{~m}$, $25 \mathrm{~m}, 35 \mathrm{~m}, 45 \mathrm{~m}, 55 \mathrm{~m}, 70 \mathrm{~m}$ and $85 \mathrm{~m}$ distance (Fig. 1). Each set consisted of 10 tensiometers installed over a width of $2 \mathrm{~m}$ at the following depths below the soil surface: $12 \mathrm{~cm}, 17 \mathrm{~cm}, 32 \mathrm{~cm}, 47 \mathrm{~cm}, 62 \mathrm{~cm}$, $77 \mathrm{~cm}, 92 \mathrm{~cm}, 107 \mathrm{~cm}, 122 \mathrm{~cm}$ and $137 \mathrm{~cm}$. At $20 \mathrm{~m}$ and $25 \mathrm{~m}$ distance from the field base the tensiometers could not be inserted at depths of $122 \mathrm{~cm}$ and $137 \mathrm{~cm}$ because of stones. A grid consisting of 96 tensiometers was hence established.

During the research period, tensiometer readings were made using an electronic tensimeter with hypodermic needle (SDEC, Reignac Sur Indre, France) at a regular basis, depending on the number of rainfall events, resulting in a total of 249 series of measurements (each series including 96 measurements). The soilwater pressure head measured with tensiometers is by definition negative in the unsaturated zone (matric head), positive in the saturated zone (hydrostatic pressure head) and zero at the interface. To evaluate the direction of water flow in the slope profile, hydraulic head profiles were constructed from the tensiometer readings. A common reference level was chosen at a depth of $1.5 \mathrm{~m}$ at the base (distance of $0 \mathrm{~m}$ ) of the experimental field plot. This allows a two-dimensional representation of water movement in the studied transect, i.e. in the vertical direction (upward and downward flow) and in the lateral direction, sub-parallel to the slope (upslope and downslope flow). It is assumed that water flow perpendicular to the longitudinal section of the experimental plot is negligible, because of a linear slope. The hydraulic head profiles are presented as equipotential lines, a graphical representation which 


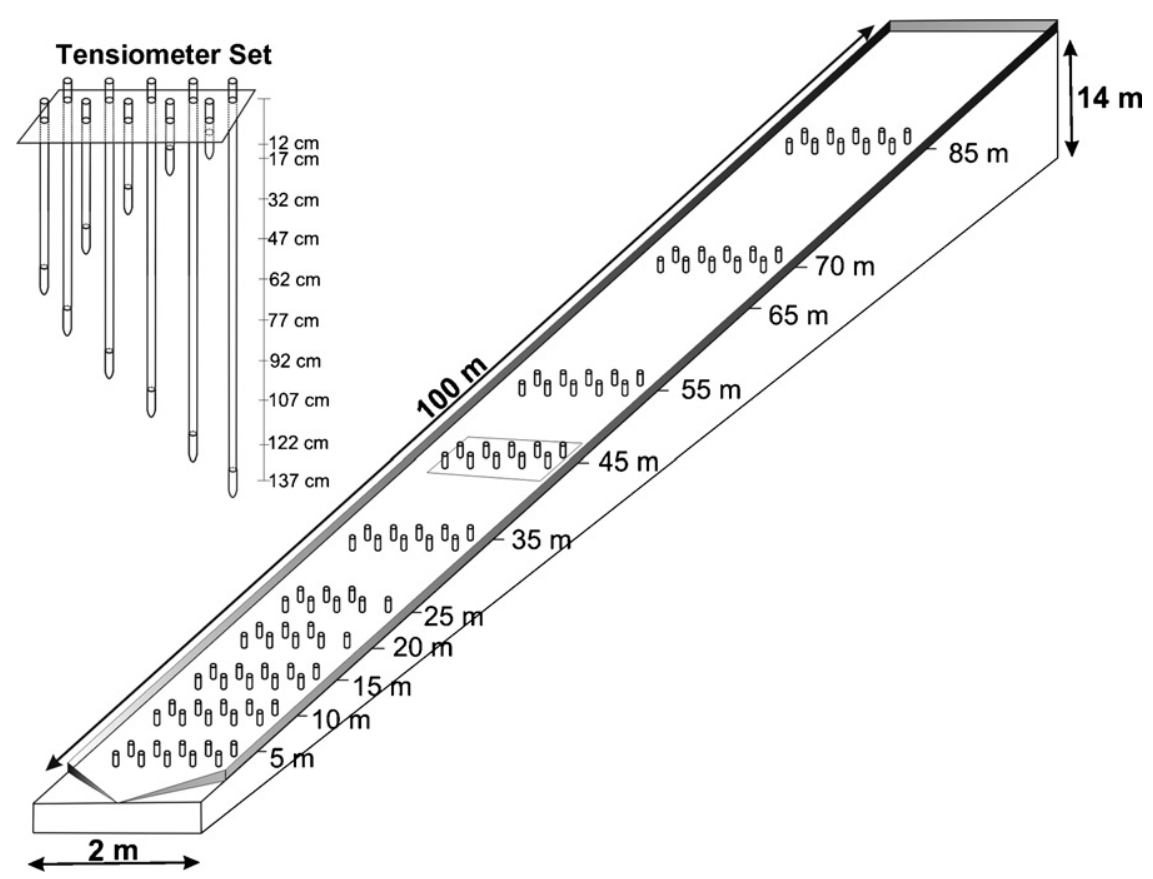

Fig. 1. Field setup at the Maarkedal experimental field.

is related to the widely used 'flow-net' method (Stephens, 1985), based on a linear interpolation between the hydraulic head values measured in the adjacent tensiometers, as often used in subsurface soil water monitoring (e.g. Anderson and Burt, 1978; Matsushi et al., 2006). In this study ordinary kriging was implemented to construct the equipotential lines (Goovaerts, 1997), using a zonal anisotropic variogram model (Pannatier, 1996). Each tensiometer was horizontally and vertically georeferenced and interpolation was performed on the pressure head values for each grid cell $(0.808 \mathrm{~m} \times 0.013 \mathrm{~m})$ along the transect. For the interpretation of the graphed equipotential lines, the following aspects need to be considered: (a) the vertical scale is exaggerated 8.5 times relative to the horizontal scale, although the relative proportions between the equipotential lines are maintained; and (b) for each point located on an equipotential line, the corresponding gravitational head can be determined by a horizontal projection on the elevation axis. The difference between the equipotential head value and the gravitational head is the soil water pressure head. The locations where the equipotential head values are equal to the height above the reference level reflect the interface between the saturated and the unsaturated zone(s) of the soil profile. This method allows the determination of the direction of water flow at every point along the slope, together with the delineation of temporary and permanently saturated zones.
Rainfall intensities were recorded in five-minutes intervals using a rain gauge (Global Water Instrumentation Inc., California, USA) located at the experimental site. Runoff from the plots was guided towards a series of calibrated tipping buckets, with a volume between 1.61 and 2.0 1. The type of instrument used resembles to the one described by Klik and Sokol (2001). The number of tips during every 5-min period was recorded using a data logger, resulting in a quasi-continuous measurement of discharge. Part of the runoff $(2.5 \%)$ was collected in barrels and proved to be representative for the average value of the sediment concentration (Verbist et al., 2003). After every runoff event, data were downloaded from the logger and runoff samples were taken from the barrels. The runoff samples were weighted and oven-dried at $105{ }^{\circ} \mathrm{C}$. After desiccation, the dried runoff samples were weighted again and the sediment concentration was calculated. The soil loss of the rain event was calculated by multiplying the total runoff amount with the sediment concentration.

\section{Results and discussion}

\subsection{Physical characterization of the plow sole}

Fig. 2 shows the penetration resistance as a function of depth at increasing distances along the plot and the average volumetric soil water content at the time of the penetration measurement. Since the experimental field 


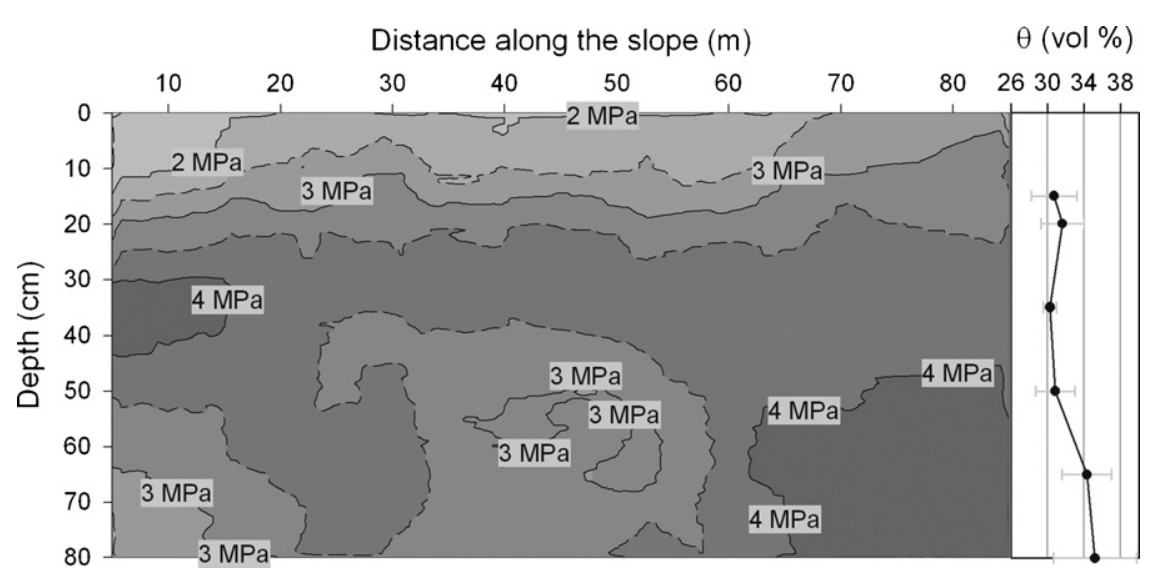

Fig. 2. Ordinary kriging interpolation of penetration resistance values (MPa) measured at different depths along the slope transect; the average volumetric moisture content $(\%)$ of the plot is indicated on the right (error bars indicate standard deviation on the mean).

was tilled continuously prior to the installation of the plots, the upper $30 \mathrm{~cm}$ of the soil profile showed comparable penetration resistances over the entire slope transect, whereas much more variability was observed below the tillage depth. A penetration resistance higher than $3 \mathrm{MPa}$ can be considered to be an impediment for root growth and is therefore often used as an indicator of soil compaction (Taylor, 1971; Callebaut et al., 1985; Ide et al., 1985). Penetration resistance values up to $4 \mathrm{MPa}$ between $20 \mathrm{~cm}$ and $40 \mathrm{~cm}$ depth indicated the occurrence of a compacted layer (plow sole). This was confirmed by a paired-samples $t$-test $(\alpha=0.05)$, where the average penetration resistance in the soil layer at $20-40 \mathrm{~cm}$ depth proved to be significantly higher, 1.5 $\mathrm{MPa}$ on average, in comparison with the upper $20 \mathrm{~cm}$. Penetration resistances in the subsoil were less

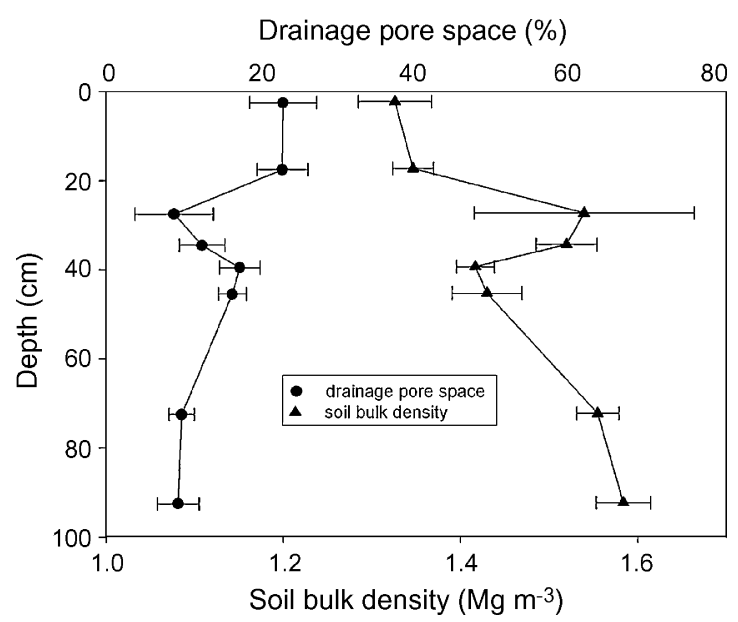

Fig. 3. Average drainage pore space (\%) and soil bulk density $\left(\mathrm{Mg} \mathrm{m}^{-3}\right)$ in function of depth $(\mathrm{cm})$ (error bars indicate the standard deviation on the mean; $n=40$ ). homogeneous in comparison with the tilled cultivated layer, indicating that values higher than $3 \mathrm{MPa}$ in the subsoil were present as well. It has been reported that compaction in the subsoil can exceed that of the plow layer (Kozicz, 1996; Lipiec and Hatano, 2003), resulting in great spatial variation of compacted zones in untilled subsoil (Tardieu, 1988), as is also the case at our field site. Additionally, the occurrence of stones in the subsoil was identified to interfere with penetration resistances at some locations (Michiels et al., 1989).

The soil bulk density and the drainage pore space for samples taken along the slope $(n=40)$ are given in Fig. 3. The drainage pore space between $25 \mathrm{~cm}$ and $37 \mathrm{~cm}$ is considerably lower, with an average value of $8.9 \pm 5.1 \%$, compared to upper and lower soil layers, with average values of $22.8 \pm 5.1 \%$ and $12.4 \pm 2.9 \%$, respectively. A paired-samples $t$-test shows that only the difference in drainage pore space between a depth of $15-20 \mathrm{~cm}$ and $25-30 \mathrm{~cm}$ is significant $(\alpha=0.05)$, with a decrease of $13.9 \pm 5.8 \%$, as well as between a depth of $32-37 \mathrm{~cm}$ and $37-42 \mathrm{~cm}$, with an increase of $5.0 \pm 2.8 \%$. This indicates a lower drainage capacity of the plow layer, resulting in a reduced hydraulic conductivity in the soil layer that was characterized by a higher penetration resistance (Fig. 2). Additionally, the soil bulk density at a depth of $25-37 \mathrm{~cm}$ shows a clear discontinuity compared with the layers above and below. This discontinuity was significant at the $95 \%$ confidence interval and analogous with the results found for drainage pore space. These results coincide with observations made by Jorajuria et al. (1997) and Pagliai et al. (2004) for conventional deep tillage systems.

Table 2 lists the average field saturated hydraulic conductivities measured at three depths $(15 \mathrm{~cm}, 30 \mathrm{~cm}$ and $45 \mathrm{~cm}$ ) using a ring infiltrometer, together with their 
Table 2

Geometric means (GM), maximum (Max) and minimum (Min) field saturated hydraulic conductivities, $K_{\mathrm{s}}$ measured in duplicate at three different depths $(\mathrm{cm})$ at three locations along the slope

\begin{tabular}{llll}
\hline & $K_{\mathrm{s}}\left(\mathrm{m} \mathrm{h}^{-1}\right)$ & & \\
\cline { 2 - 4 } & 15 & 30 & 65 \\
\hline$n$ & 6 & 6 & $5.2 \mathrm{E}-03$ \\
$K_{\mathrm{GM}}$ & $3.1 \mathrm{E}-02 \mathrm{a}^{\dagger}$ & $2.5 \mathrm{E}-04 \mathrm{a}$ & $2.7 \mathrm{E}-02$ \\
$K_{\max }$ & $3.2 \mathrm{E}-01$ & $6.8 \mathrm{E}-02$ & $1.0 \mathrm{E}-03$ \\
$K_{\min }$ & $7.0 \mathrm{E}-03$ & $1.0 \mathrm{E}-04$ & \\
\hline
\end{tabular}

${ }^{\dagger}$ Same letter in the row of geometric means indicates that they were significantly different at $\alpha=0.05$.

minimum and maximum values $(n=18)$. Based on these measurements, the soil layers at a depth of $15 \mathrm{~cm}$, $30 \mathrm{~cm}$ and $45 \mathrm{~cm}$ hence can be classified as respectively medium, low and medium permeable (Klute and Dirksen, 1986). Statistical analysis, using a pairedsamples $t$-test, indicates that the hydraulic conductivity of the upper layer is significantly larger than that from deeper layers at the $95 \%$ confidence interval $(\alpha=0.05)$. This is in accordance with the observed reduction in drainage pore space and the increase in soil bulk density in this soil layer (Fig. 3). Although the mean hydraulic conductivity of the plow layer was smaller than that from below $(45 \mathrm{~cm})$, they were not significantly different $(\alpha=0.05)$. Since soil bulk density tends to increase with depth (Fig. 3), smaller hydraulic conductivities are to be expected in comparison with the upper soil layer.

Clear reductions in saturated hydraulic conductivity due to subsoil compaction have been related to a reduction of the larger pores $(>50 \mu \mathrm{m})$ (Pagliai et al., 2000; Lin et al., 1996), as well as to a change in pore geometry (Assouline et al., 1997) and to a reduction of pore continuity (Lipiec and Hatano, 2003; Weiskopf et al., 2000). Pagliai et al. (2004) reported a $90 \%$ decrease in saturated hydraulic conductivity at the plow layer depth, consistent with Lin et al. (1996) who reported that a reduction of $10 \%$ of the macropores $(>50 \mu \mathrm{m})$ is responsible for a $89 \%$ reduction of the total water flux.

\subsection{Occurrence of a temporary water table}

Analyzing matric heads during the measuring period revealed rapid responses of the top layer to small rainfall events. In various occasions, the top soil was saturated during or after the rainfall, whereas the lower lying zone showed unsaturated conditions until the permanent groundwater table was reached. In Fig. $4 a-c$, three examples of such behavior are shown, for 10 and 11 March 2003, for 19 January 2004 and for 6 and 7 April 2004. In all cases, maximal rainfall intensities were very low, as indicated in Fig. 4, and far below the
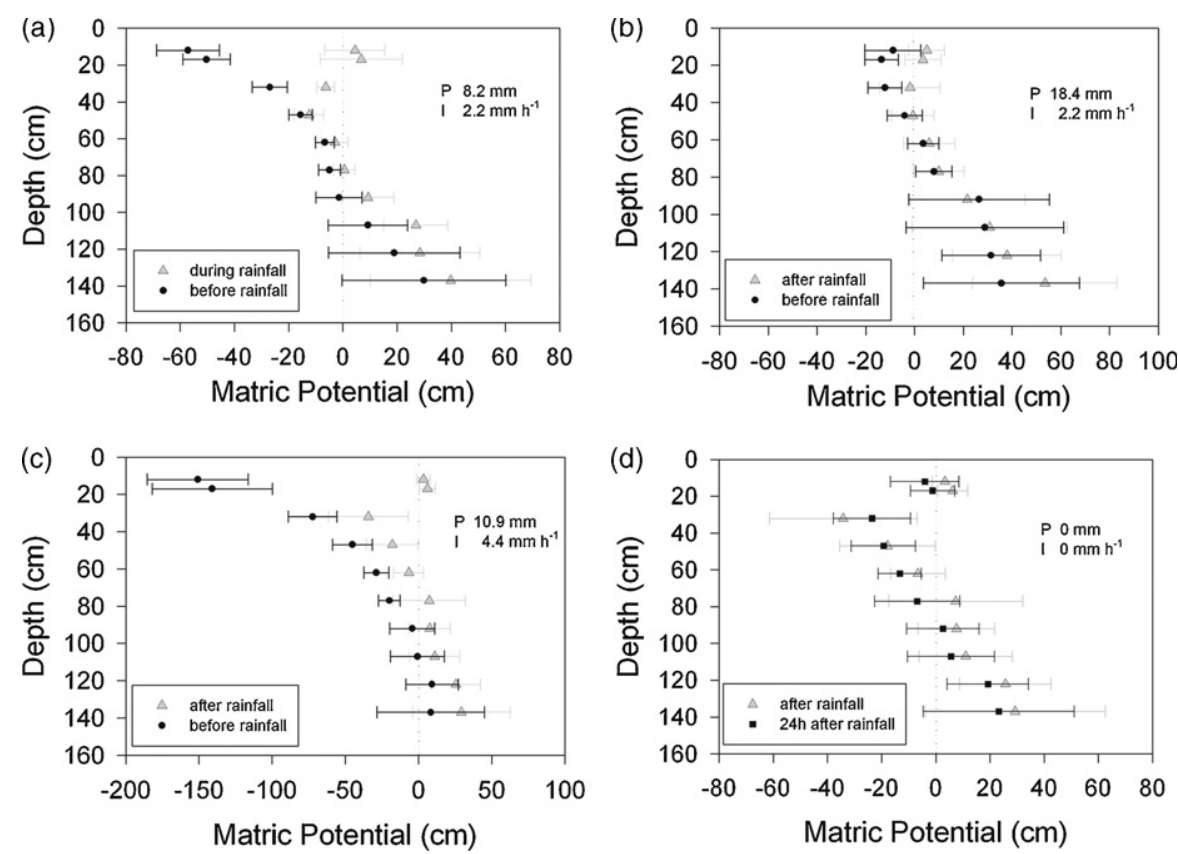

Fig. 4. Average matric heads measured before and after (or during) rainfall events at 10 and 11 March 2003 (A) 19 January 2004 a.m. and p.m. (B), 6 and 7 April 2004 (C) and (D) shows the pressure heads at 7 and 8 April 2004 (error bars indicate the standard deviation on the mean; $n=10$ ); P means the total rainfall $(\mathrm{mm})$ and $\mathrm{I}$ the maximal 5-min rainfall intensity $\left(\mathrm{mm} \mathrm{h}^{-1}\right)$. 
measured saturated hydraulic conductivity of the top soil $\left(22.0 \mathrm{~mm} \mathrm{~h}^{-1}\right)$. The soil matric head is shown as an average of 10 measurements taken at increasing distances from the lowest point of the slope (see Fig. 1) with indication of the standard deviation on the spatially distributed measurements. Examples (a) and (c) show comparable conditions, where after a dry period with negative pressure heads near to the soil surface, pressure heads increase rapidly at $12 \mathrm{~cm}$ and $17 \mathrm{~cm}$ depth during and after the rain event, producing saturated conditions in the top layer, whereas still negative pressure heads are observed at $32 \mathrm{~cm}, 47 \mathrm{~cm}$ and $62 \mathrm{~cm}$ depth. Example (b) shows already nearsaturated top soil conditions before the rainfall event started, resulting in a less pronounced increase in pressure head. Apparently, in these cases, free drainage in the soil profile is limited and a perched water table is developed in at least the upper $17 \mathrm{~cm}$ of the soil. These observations are a logical consequence of the soil physical characteristics observed at the different soil depths and indicate that vertical water movement in the soil profile is restricted by a layer of low conductivity, present at the compacted plow layer depth (Table 2).

When considering measurements performed $24 \mathrm{~h}$ after a rainfall event (Fig. 4d), soil water matric heads in the top tensiometers still show near-saturated conditions, whereas the pressure heads at $32 \mathrm{~cm}$ and below are not significantly influenced by the rain event at the 95\% confidence interval. This adds to the evidence that, on average, vertical water movement was reduced or even restrained by the plow layer.

Fig. 5 represents interpolated matric heads for each of the three rainfall events presented in Fig. 4a-c. The rainfall event of March 112003 (plot A) shows a saturated top soil in the first section of the slope overlying an unsaturated layer, whereas plots B and C, showing field conditions after the rainfall events recorded on 19 January 2004 and 7 April 2004 respectively, indicate a complete saturation of the top soil and a limited drainage to underlying layers. This suggests the production of variable source areas at different locations along the slope, contributing to surface runoff by limiting further infiltration (saturation excess rainfall) on the one hand and by generating return flow on the other hand.

To illustrate this behavior at the field scale even in more detail, hydraulic head values measured on 11 March 2003 (Fig. 4a) are graphically presented as equipotential lines (Fig. 6). Note that the gravitational head is presented by the vertical axis in this representation. Where the hydraulic head exceeds the gravitational head, the pressure head is positive, indicating saturated conditions. When the difference between hydraulic head and gravitational head is negative, unsaturated conditions are present. In accordance with Fig. 5, the hydraulic heads in Fig. 6 show two distinct saturated zones, the groundwater table and a perched water table in the first $50 \mathrm{~m}$ of the slope, divided by an intermediate unsaturated soil layer. More important, Fig. 6 also indicates the direction of subsurface water flow, perpendicular to the equipotential lines. Whereas the direction of flow is mainly vertical in the upper part of the slope, in the saturated top layer the equipotential lines clearly indicate the occurrence of subsurface flow parallel to the slope, in a downward direction. The occurrence of a lateral component in the subsurface flow of the perched water table suggests that this process increases saturation downslope and will eventually contribute to surface runoff processes, through saturation excess runoff.

For shallow soils, a number of studies have used a visualization of hydraulic head lines to identify a lateral component in subsurface flow (Weyman, 1973; Wheater et al., 1987; Retter et al., 2006 and Matsushi
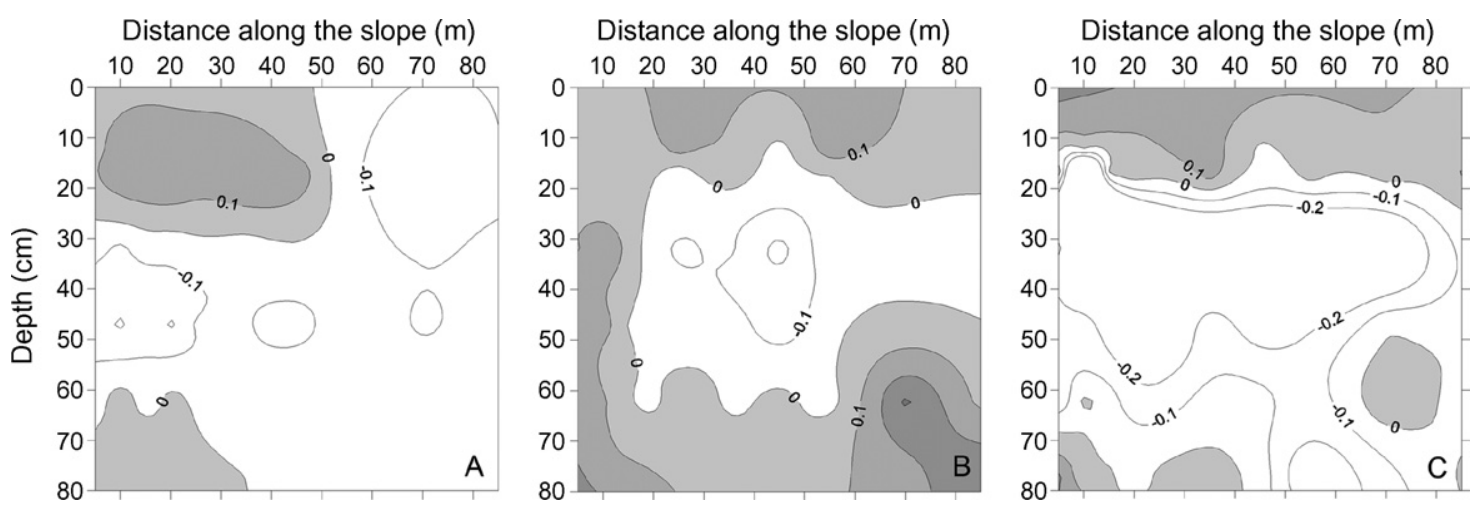

Fig. 5. Ordinary kriging interpolation of matric heads (m) measured after rainfall events at 11 March 2003 (A), 19 January 2004 (B) and 7 April 2004 (C). 


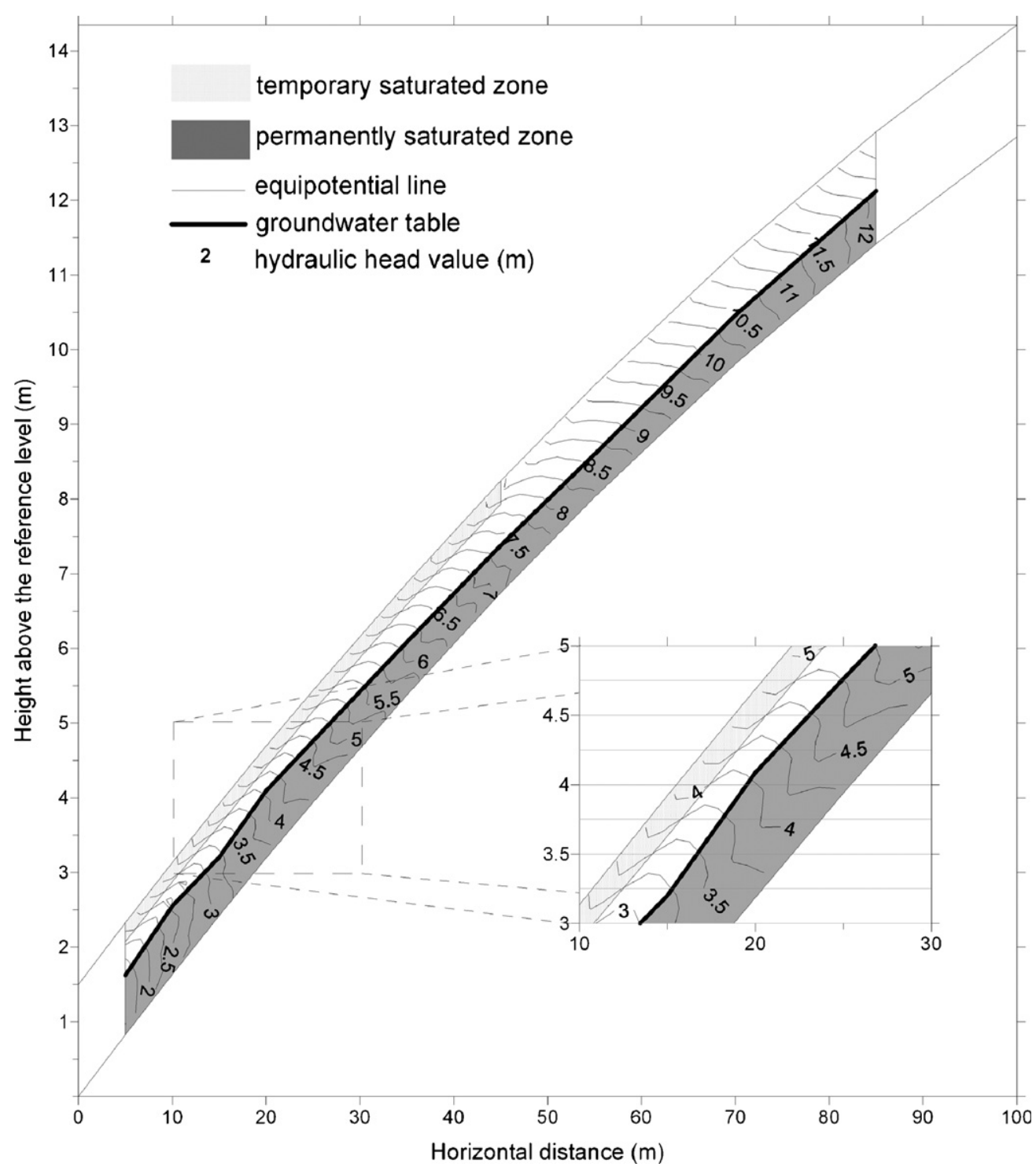

Fig. 6. Ordinary kriging interpolation of hydraulic head values (equipotential lines) during the rainfall event of 11 March 2003, showing a temporary saturated zone in the top soil at the moment when runoff generation was initiated; the inset shows an enlargement of part of the graph.

et al., 2006). The results presented in this study show a comparable behavior for deep soils where tillage practices have created a compacted layer that inhibits free drainage.

\subsection{Influence of the plow sole on runoff}

To evaluate the influence of top soil saturation on runoff production for the whole measuring period, measured pressure heads were compared with runoff amounts. Fig. 7 shows the pressure heads from the readings at $12 \mathrm{~cm}$ and $17 \mathrm{~cm}$ depth and the measured runoff volumes during the period December 2002 to
July 2003. It can be observed that the runoff data follow the matric head values rather well.

During the study period, 74 rainfall events with more than $1 \mathrm{~mm}$ of rainfall were recorded and data on maximal rainfall intensity, runoff amount and pressure head of the top layer during or shortly after the rainfall event were collected. These data were reclassified, indicating unsaturated $(<0 \mathrm{~cm}$ pressure head) or saturated conditions $(\geq 0 \mathrm{~cm}$ pressure head), and whether runoff occurred or not (Table 3). Depending on the maximal 5-min rainfall intensity recorded, the rainfall event was classified as having a low $\left(1-5 \mathrm{~mm} \mathrm{~h}^{-1}\right)$, medium $\left(5-10 \mathrm{~mm} \mathrm{~h}^{-1}\right)$ or high $\left(>10 \mathrm{~mm} \mathrm{~h}^{-1}\right)$ rainfall intensity. 


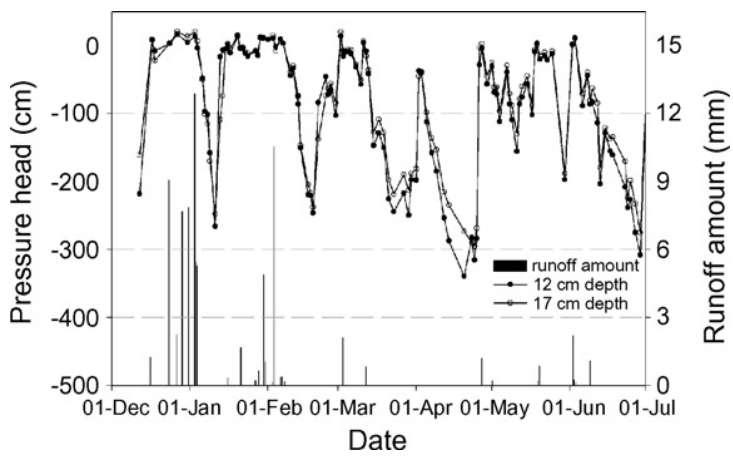

Fig. 7. Evolution of the pressure head at 12 and $17 \mathrm{~cm}$ depth from 1 December to 1 July 2003; the amount of runoff is indicated on the same time scale (bars).

Table 3

Summary of rainfall events $(n=74)$ during the measuring period, indicating top soil saturated (TS Sat) or unsaturated (TS UnSat) conditions, and the occurrence of runoff (R) or not (No R); Rainfall events are reclassified by their maximal rainfall intensities as Low $\left(1-5 \mathrm{~mm} \mathrm{~h}^{-1}\right)$, Medium $\left(5-10 \mathrm{~mm} \mathrm{~h}^{-1}\right)$ or High $\left(>10 \mathrm{~mm} \mathrm{~h}^{-1}\right)$

\begin{tabular}{|c|c|c|c|c|c|c|c|c|}
\hline & \multicolumn{2}{|c|}{ All events } & \multicolumn{6}{|c|}{ Maximal rainfall intensity } \\
\hline & \multirow[t]{2}{*}{$\mathrm{R}$} & \multirow[t]{2}{*}{ No $R$} & \multicolumn{2}{|c|}{ Low } & \multicolumn{2}{|c|}{ Medium } & \multicolumn{2}{|c|}{ High } \\
\hline & & & $\mathrm{R}$ & No R & $\mathrm{R}$ & No $R$ & $\mathrm{R}$ & No $R$ \\
\hline TS Sat & 30 & 3 & 21 & 3 & 5 & 0 & 4 & 0 \\
\hline TS UnSat & 25 & 16 & 11 & 10 & 3 & 6 & 11 & 0 \\
\hline
\end{tabular}

Cross tabulating variables showed that under conditions of top soil saturation $91 \%$ of the rainfall events led to runoff, against $61 \%$ for unsaturated conditions (Table 3). In order to evaluate the influence of top soil saturation on runoff, the relative risk was calculated, defined as the probability of an event to occur in the presence of an influencing factor compared with the probability of this event to occur in the absence of the influencing factor. Selecting top soil saturation as this factor, the relative risk that runoff occurs is 1.49 times higher with saturation than without saturation.

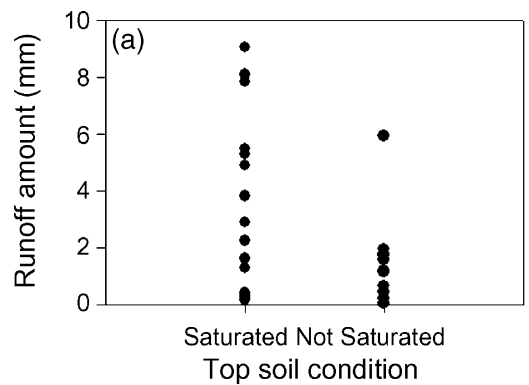

Finally, the effect of maximal rainfall intensity recorded during the rainfall events was incorporated in the analysis, dividing the results in three groups. For the rainfall intensity classes low, medium and high, respectively $88 \%, 100 \%$ and $100 \%$ of the rainfall events with saturated conditions of the top soil caused runoff (Table 3 ). This indicates that only under small rainfall intensities, saturation of the top soil does not lead to runoff in all cases. For the highest rainfall intensity class, the occurrence of runoff cannot be assigned completely to saturation excess runoff, since rainfall intensities are in the range of the saturated hydraulic conductivity of the soil surface. Indeed, in this class all rainfall events caused runoff and $73 \%$ occurred under unsaturated top soil conditions. For the lowest two rainfall intensity classes, respectively $66 \%$ and $63 \%$ of the runoff events were related to saturation excess runoff, due to top soil saturation.

Apart from the occurrence of runoff, the amount of runoff was also correlated to top soil saturation, as shown in Fig. 8a. Nevertheless, no direct correlation was observed between the occurrence of top soil saturation and the amount of soil loss (Fig. 8b). This can be attributed to the high variation of this parameter and to the fact that rainfall intensity is a far more important factor in explaining the soil loss variance. Soil losses observed during erosion events under saturated conditions of the top soil (30 events) totaled $5.0 \mathrm{t} \mathrm{ha}^{-1}$, compared with a total soil loss of $7.4 \mathrm{t} \mathrm{ha}^{-1}$ under unsaturated conditions ( 25 events).

\section{Summary and conclusions}

In this study we demonstrated that on a sloping field, subsoil compaction can affect surface runoff production. The presence of a plow sole was confirmed by measurements of penetration resistance, soil density and drainage pore space. A reduced drainage capacity and increased soil bulk density was observed at a depth of $30 \mathrm{~cm}$, which was identified as the common plowing

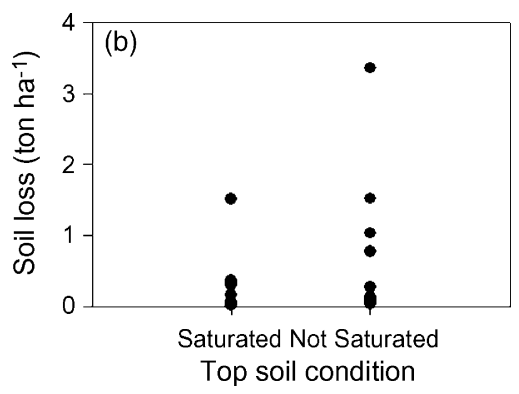

Fig. 8. Relation between the occurrence of a perched water table on top of the compacted plow sole and the amount of runoff (A) and soil loss (B). 
depth. Ring infiltrometer measurements confirmed a steep reduction in the field saturated hydraulic conductivity at a depth of $30 \mathrm{~cm}$.

Tensiometer measurements showed the formation of a perched water table on top of the compacted plow layer, clearly indicating a limited water movement due to compaction, as would be expected from the results presented in the first section. Additionally, the direction of subsurface flow was found to be parallel to the sloped soil surface and may contribute to the production of saturation excess runoff downslope. However, the actual temporal resolution of the tensiometer measurements was insufficient to model the water balance and to identify the individual soil water fluxes. Although the actual set-up was sufficient to observe the occurrence of a perched water table on top of a compacted layer, an automated recording system for tensiometer readings would be advisable for similar future research to gain insight in the small temporal changes of pressure heads in every soil layer and to visualize the formation and behavior of variable source areas along the slope.

Descriptive and statistical tests show that saturation excess runoff, caused by the occurrence of a perched water table on top of the plow layer, is an important factor in runoff production and consequent erosion on the field plot. Runoff was observed in almost all cases when the top soil was saturated $(91 \%)$ and in all cases when rainfall intensities increased. The risk of runoff occurrence was calculated to be $50 \%$ higher under saturated top soil conditions. Furthermore, runoff occurrence under rainfall intensities ranging from $1 \mathrm{~mm} \mathrm{~h}^{-1}$ to $5 \mathrm{~mm} \mathrm{~h}^{-1}$ and from $5 \mathrm{~mm} \mathrm{~h}^{-1}$ to $10 \mathrm{~mm} \mathrm{~h}^{-1}$ was for $63 \%$ and $66 \%$ respectively associated with the development of a perched table in the top layer.

Based on these observations, it is concluded that a compacted plow sole increases the number of runoff events, due to saturation excess runoff, mostly under rainfall intensities that otherwise would not produce runoff and erosion.

\section{Acknowledgements}

The authors would like to thank Jan Restiaen and Eric Delmulle for their assistance during the field measurements and laboratory work.

\section{References}

Anderson, M.G., Burt, T.P., 1978. Toward more detailed field monitoring of variable source areas. Water Resour. Res. 14, 1123-1131.
Arvidsson, J., 2001. Subsoil compaction caused by heavy sugarbeet harvesters in southern Sweden. Part I. Soil physical properties and crop yield in six field experiments. Soil Till. Res. 60, 67-78.

Assouline, S., Tavares-Filho, J., Tessier, D., 1997. Effect of compaction on soil physical and hydraulic properties: experimental results and modeling. Soil Sci. Soc. Am. J. 61, 390-398.

Bennie, A.T.P., Burger, R.du.T., 1988. Penetration resistance of fine sandy apedal soils as affected by bulk density, water content and texture. S. Afr. J. Plant Soil 5, 5-10.

Callebaut, F., Gabriels, D., Minjauw, W., De Boodt, M., 1985. Determination of soil surface strength with a needle-type penetrometer. Soil Till. Res. 5, 227-245.

Coates, D.R., 1990. The relation of subsurface water to downslope movement and failure. In: Higgins, C.G., Coates, D.R. (Eds.), Groundwater Geomorphology: Role of Subsurface Water in EarthSurface Processes and Landforms. Geological Society of America Special Paper 252, Boulder, Colo.

Dunne, T., Black, R.D., 1970. Partial area contributions to storm runoff in a small New England watershed. Water Resour. Res. 6 (5), 1296-1311.

Dunne, T., Moore, T.R., Taylor, C.H., 1975. Recognition and prediction of runoff-producing zones in humid regions. Hydrol. Sci. Bull. 20, 305-327.

Fies, J.C., 1971. Recherche d'une interprétation texturale de la porosité des sols. Ann. Agron. 22 (6), 655-685.

Fullen, M.A., 1985. Compaction, hydrological processes and soil erosion on loamy sands in east Shropshire. Engl. Soil Till. Res. 6 (1), 17-29.

Gee, G.W., Bauder, J.W., 1986. Particle size analysis. In: Klute, A. (Ed.), Methods of Soil Analysis. Part 1. American Society of Agronomy, Madison, WI, pp. 383-411.

Goovaerts, P., 1997. Geostatistics for Natural Resources Evaluation. Oxford University Press, Oxford.

Guérif, J., 1987. L'analyse de la porosité: Application a l'étude du compactage des sols. In: Monnier, G., Goss, M.J. (Eds.), Soil Compaction and Regeneration., AA Balkema, Rotterdam, pp. 113.

Hagerty, D.J., 1991. Piping/sapping erosion. 1. Basic considerations. J. Hydraul. Eng. 117 (8), 991-1008.

Hewlett, J.D., Hibbert, A.R., 1967. Factors affecting the response of small watersheds to precipitation in humid areas. In: Sooper, W.E., Lull, H.W. (Eds.), Forest Hydrology. Pergamon Press, Oxford, pp. 275-290.

Higgins, C.G., Coates, D.R., 1990. Groundwater geomorphology: role of subsurface water in earth-surface processes and landforms. Geological Society of America Special Paper 252, Boulder, Colo.

Horton, R.E., 1933. The role of infiltration in the hydrological cycle. Trans. Am. Geophys. Union 14, 446-460.

House, M.L., Powers, W.L., Eisenhauer, D.E., Marx, D.B., Fekersillassie, D., 2001. Spatial analysis of machine-wheel traffic effects on soil physical properties. Soil Sci. Soc. Am. J. 65, 1376-1384.

Ide, G., Hofman, G., Van Ruymbeke, M., Ossemerct, C., 1985. The influence of subsoiling a plowsole on water and nutrient uptake, on root growth and on the yield of corn crops. Pedologie 3, 265-281.

Jorajuria, D., Draghi, L., Aragon, A., 1997. The effect of vehicle weight on the distribution of compaction with depth and the yield of Lolium/Trifolium grassland. Soil Till. Res. 41 (1-2), 1-12.

Kirkby, M.J., 1978. Implications for sediment transport. In: Kirkby, M.J. (Ed.), Hillslope Hydrology. Wiley, Chichester, UK, pp. 325364. 
Kirkby, M.J., Chorley, R.J., 1967. Throughflow, overland flow, and erosion. Int. Assoc. Sci. Hydrol. Bull. 12 (3), 5-21.

Klik, A., Sokol, W., 2001. A new measuring device for field erosion plots. In: American Society of Agricultural Engineers (Eds.)Proceedings of the International Symposium on Soil Erosion Research for the 21st Century, January 2-5, 2001, Honolulu, Hawaii, pp. 234-236.

Klute, A., Dirksen, C., 1986. Hydraulic conductivity and diffusivity: laboratory methods. In: Klute, A. (Ed.), Methods of Soil Analysis. Part 1. Agronomy, vol. 9. ASA and SSSA publish, Madison, WI, pp. 687-734.

Kozicz, J., 1996. Compacting soil with traction mechanisms of aggregates at cultivating cereals and root crops. Post. Nauk Rol. 4, 51-64.

Lin, H.S., McInnes, K.J., Wilding, L.P., Hallmark, C.T., 1996. Effective porosity and flow rate with infiltration at low tensions in a well-structured subsoil. Trans. ASAE 39, 131-133.

Lipiec, J., Hatano, R., 2003. Quantification of compaction effects on soil physical properties and crop growth. Geoderma 116, 107-136.

Matsushi, Y., Hattanji, T., Matsukura, Y., 2006. Mechanisms of shallow landslides on soil-mantled hillslopes with permeable and impermeable bedrocks in the Boso Peninsula, Japan. Geomorphology 76, 92-108.

McGarry, D., 2001. Tillage and soil compaction. In: García-Torres, Benites, L., Martínez-Vilela, A. (Eds.), Proceedings of the I World Congres on Conservation Agriculture, Keynote Contributions, vol. 1, October 1-5, 2001, XUL, Córdoba, Madrid, pp. 281-291.

Michiels, P., Hartmann, R., De Strooper, E., 1989. Subsurface water flow on a slope in the loamy region of Belgium. Earth Surf. Processes 14, 533-543.

Pagliai, M., 1987. Micromorphometric and micromorphological investigations on the effect of compaction by pressures and deformations resulting from tillage and wheel traffic. In: Monnier, G., Goss, M.J. (Eds.), Soil Compaction and Regeneration, AA Balkema, Rotterdam, pp. 31-38.

Pagliai, M., Marsili, A., Servadio, P., Vignozzi, N., Pellegrini, S., 2003. Changes in some physical properties of a clay soil in Central Italy following the passage of rubber tracked and wheeled tractors of medium power. Soil Till. Res. 73, 119-129.

Pagliai, M., Pellegrini, S., Vignozzi, N., Rousseva, S., Grasselli, O., 2000. The quantification of the effect of subsoil compaction on soil porosity and related physical properties under conventional to reduced management practices. In: Horn, R., van den Akker, J.J.H., Arvidsson, J. (Eds.), Subsoil Compaction-Distribution, Processes and Consequences. Adv. Geoecol., vol. 32. Catena, Reiskirchen, Germany, pp. 305-313.

Pagliai, M., Vignozzi, N., Pellegrini, S., 2004. Soil structure and the effect of management practices. Soil Till. Res. 79, 131-143.

Pannatier, Y., 1996. Variowin, Software for Spatial Data Analysis in 2D. Springer-Verlag, New York.

Radford, B.J., Bridge, B.J., Davis, R.J., McGarry, D., Pillai, U.P., Rickman, J.F., Walsh, P.A., Yule, D.F., 2000. Changes in the properties of a Vertisol and responses of wheat after compaction with harvester traffic. Soil Till. Res. 54, 155-170.
Retter, M., Kienzler, P., Germann, P.F., 2006. Vectors of subsurface stormflow in a layered hillslope during runoff initiation. Hydrol. Earth Syst. Sci. 10, 309-320.

Smith, C.W., Johnston, M.A., Lorentz, S., 1997. The effect of soil compaction and soil physical properties on the mechanical resistance of South African forestry soils. Geoderma 78, 93-111.

Stephens, D.B., 1985. A field method to determine unsaturated hydraulic conductivity using flow nets. Water Resour. Res. 21, 45-50.

Tardieu, F., 1988. Analysis of the spatial variability of maize root density. Part I. Effect of wheel compaction on the spatial arrangement of roots. Plant Soil 107, 259-266.

Taylor, H.M., 1971. Effects of soil strength on seedling emergence, root growth and crop yield. In: Barnes, K.K., Carleton, W.M., Taylor, H.M., Throckmorton, R.I., Vandenberg, G.E. (Eds.), Compaction of Agricultural Soils. ASAE. Monogr., St. Joseph, pp. 292-305.

USDA, 1998. Keys to Soil Taxonomy, 8th ed. Dep. Agric. Nat. Res. Cons. Serv, Washington.

Verbist, K., Schiettecatte, W., 2004. Using WEPP for single rainfall event prediction in Belgium. In: Visser, S.M., Cornelis, W.M. (Eds.), Wind and Rain Interaction in Erosion. Tropical Resources Management Papers 50, pp. 33-41.

Verbist, K., Schiettecatte, W., Gabriels, D., 2003. Usability of rainfall simulation experiments to assess soil erosion under natural rainfall. In: Gabriels, D., Cornelis, W.M. (Eds.), Proceedings of the International Symposium on 25 years of assessment of erosion, September 22-26, 2003, Ghent, Belgium, pp. 269-276.

Voorhees, W.B., Nelson, W.W., Randall, G.W., 1986. Extent and persistence of subsoil compaction caused by heavy axle loads. Soil Sci. Soc. Am. J. 50, 428-433.

Walkley, A., Black, J.A., 1934. An examination of the Degtjareff method for determining soil organic matter and a proposed modification of the chromic titration method. Soil Sci. 37, 29-38.

Warrick, A.W., Nielsen, D.R., 1980. Spatial variability for soil physical properties in the field. In: Hillel, D. (Ed.), Applications of Soil Physics. Academic Press, Toronto, pp. 319-344.

Weiskopf, P., Zihlman, U., Wiermann, C., Horn, R., Anken, Th., Diserens, E., 2000. Influence of conventional and onland-ploughing on soil moisture. In: Horn, R., van den Akker, J.J.H., Arvidsson, J. (Eds.), Subsoil Compaction-Distribution, Processes and Consequences. Adv. Geoecol., vol. 32, Catena, Reiskirchen, Germany, pp. 37-81.

Weyman, D.R., 1973. Measurements of the downslope flow of water in a soil. J. Hydrol. 20, 267-288.

Wheater, H.D., Langan, S.J., Miller, J.D., Ferrier, R.C., 1987. The determination of hydrological flow paths and associated hydrochemistry in forested catchments in central Scotland, IAHS Pub. No. 167, Proc. Vancouver Symsium.

Wilson, G.V., Jardine, P.M., Luxmore, R.J., Zelazny, L.W., Lietzke, D.A., Todd, D.E., 1991. Hydrogeochemistry processes controlling subsurface transport from an upper subcatchment of Walker Branch watershed during storm events. 1. Hydrologic transport processes. J. Hydrol. 123 (3/4), 297-316. 